\title{
The Obesity Paradox Existing in Idiopathic Pulmonary Arterial Hypertension
}

\author{
๑ Bihter Şentürk1, ๑ Bahri Akdeniz1, ๑ Ebru Özpelit1, ๑ Mehmet Birhan Yılmaz1, \\ ๑ Buse Özcan Kahraman², ๑ Dilek Sezgin 3 , ๑ Kemal Can Tertemiz ${ }^{4}$, ๑ Can Sevinç4
}

\footnotetext{
1Dokuz Eylül University Faculty of Medicine, Department of Cardiology, İzmir, Turkey

2Dokuz Eylül University School of Physical Therapy and Rehabilitation, İzmir, Turkey

${ }^{3}$ Dokuz Eylül University Faculty of Nursing, Department of Internal Medicine Nursing İzmir, Turkey

${ }^{4}$ Dokuz Eylül University Faculty of Medicine, Department of Chest Disease, İzmir, Turkey
}

\begin{abstract}
Objectives: Our purpose was to evaluate the association between idiopathic pulmonary arterial hypertension $(\mathrm{PAH})$ and obesity, as indicated by the body-mass index (BMI), in terms of the all-cause mortality in a group of patients from a specialized center.

Materials and Methods: In this study, we retrospectively analyzed 78 consecutive adult patients with idiopathic PAH. The patients were classified into two groups as the deceased (D) and the survived (S). A set of data was collected for each patient, including gender, age, weight, height, BMI $\left(\mathrm{kg} / \mathrm{m}^{2}\right)$, World Health Organization functional class (WHO FC), brain natriuretic peptide (BNP), hemoglobin, the presence of atrial fibrillation (AF), 6-minute walking distance (6MWD), echocardiographic and hemodynamic parameters.
\end{abstract}

Results: The mean follow-up period was 33.7 months (maximum: 128 months), 38 deaths (48.7\%) were noted.
The two groups were found to be similar in terms of gender, age, and the presence of AF. The median BNP level in group $\mathrm{D}$ was significantly higher than that in group S $(p<0.001)$. Baseline WHO FC III-IV was significantly more common in group D than that in group $\mathrm{S}(89.5 \%$ vs $57.5 \%, \mathrm{p}=0.003)$. Group D had significantly lower BMI and $6 \mathrm{MWD}$ compared to those in group $\mathrm{S}(\mathrm{p}<0.001$ and $\mathrm{p}=0.017$, respectively). Multivariate logistic regression analysis showed that BMI [Odds ratio $(\mathrm{OR})=0.632,95 \%$ confidence interval $(\mathrm{CI})=0.478-0.837, \mathrm{p}=0.001]$ and 6MWD $\quad(\mathrm{OR}=0.981, \quad 95 \% \quad \mathrm{CI}=0.970-0.993, \quad \mathrm{p}=0.002)$ were independent predictors of mortality in this cohort. The receiver operating characteristic curve analysis was performed to assess the utility of BMI as a predictor of mortality. The optimal BMI cut-off was $24.25 \mathrm{~kg} / \mathrm{m}^{2}$, with $60.5 \%$ sensitivity and $82.5 \%$ specificity (area under the curve $=0.759,95 \% \mathrm{CI}=0.654-0.864, \mathrm{p}<0.001)$ and the

Address for Correspondence: Bihter Şentürk, Dokuz Eylül University Faculty of Medicine, Department of Cardiology, İzmir, Turkey Phone: +90 5325164926 e-mail: drbihter@hotmail.com ORCID: orcid.org/0000-0003-3568-4476

Received: 01.03.2020 Accepted: 22.04.2020

Cite this article as: Şentürk B, Akdeniz B, Özpelit E, Yılmaz MB, Özcan Kahraman B, Sezgin D, Tertemiz KC, Sevinç C. The Obesity Paradox Existing in Idiopathic Pulmonary Arterial Hypertension. EJCM 2020;8(2):78-84.

DOI: 10.32596/ejcm.galenos.2020.02.011 


\section{Abstract}

patients with a BMI of $\leq 24.25$ had worse prognosis based on the Kaplan Meier analysis survival curves (log-rank $\mathrm{p}<0.004)$.

Conclusion: BMI seems to be linearly but inversely related to all-cause mortality among patients with idiopathic PAH.
Keywords: Pulmonary arterial hypertension, obesity paradox, body-mass index, mortality

\section{Introduction}

Pulmonary arterial hypertension $(\mathrm{PAH})$ is characterized by the dynamic obstruction of pulmonary vasculature by vasoconstriction, pathologically non-compliant arteries, and adverse vascular re-modelling due to vascular fibrosis and stiffening. Pulmonary vascular resistance (PVR) is increased because of obstruction, hyperproliferation in pulmonary vascular bed and the vasoconstriction of precapillary arterioles, resulting in increased right ventricular (RV) afterload and right heart failure, which are the major causes of mortality in patients with $\mathrm{PAH}^{(1)}$.

On the other hand, there has been a marked increase in the worldwide prevalence of obesity over recent decades, which has increased the overall disease burden and resulted in millions of deaths annually ${ }^{(2)}$. Obesity is associated with several health problems, including the increased risk of cardiovascular and respiratory diseases ${ }^{(3-5)}$.

In this study, our purpose was to evaluate the association between idiopathic PAH and obesity, as indicated by the body-mass index (BMI), in terms of the all-cause mortality in a group of patients from a specialized center.

\section{Materials and Methods}

\section{Study population}

The study was approved by the Non-invasive Research Ethics Board of Dokuz Eylul University (number: 2018/07-31). In this study, we retrospectively analyzed 78 consecutive adult patients with idiopathic $\mathrm{PAH}$, who met the diagnostic criteria for definitive PAH based on the European Society of Cardiology/European
Respiratory Society Guideline, between January 2008 and December 2019. In the guideline, PAH is defined by a mean pulmonary artery pressure (PAP) of $\geq 25 \mathrm{mmHg}$ (at rest), a pulmonary capillary wedge pressure of $\leq 15$ $\mathrm{mmHg}$, and a PVR of $>3$ Wood units in the right heart catheterization (RHC) assessments ${ }^{(6)}$. A set of data was collected for each patient, including gender, age, weight, height, BMI $\left(\mathrm{kg} / \mathrm{m}^{2}\right)$, World Health Organization functional class (WHO FC), brain natriuretic peptide (BNP), hemoglobin, the presence of atrial fibrillation (AF), 6-minute walking distance (6MWD), echocardiographic and hemodynamic parameters. Allcause mortality (ACM) was noted during the follow up with 3-month intervals. The BMI was calculated at the time of baseline RHC by dividing the mass in kilograms by the square of the height in meters ${ }^{(7)}$. Patients with unreported height or weight at admission were excluded. All patients had diagnostic RHC at rest by an experienced cardiologist.

A thorough transthoracic echocardiography that specifically focused on investigating the function, dimension and the pressure within the right side of the heart was performed. The tricuspid annular plane systolic excursion (TAPSE) and the RV end-diastolic diameter were measured. Systolic PAP was calculated. The existence of pericardial effusion was recorded.

\section{Statistical Analysis}

Statistical analyses were performed using SPSS 25.0 (SPSS Inc., Chicago, USA). The normality was assessed with the Kolmogorov-Smirnov test, and the data were 
reported as percentages for categorical variables, mean \pm standard deviation for continuous variables, and median (IQR) when the distribution was not normal. Student's $t$-test and the appropriate chi-square test were used for comparing the groups for continuous and categorical variables, respectively. In order to predict mortality in PAH patients, the optimal cut-off threshold for the BMI was obtained by analyzing the receiver operating characteristic (ROC) curve. The Kaplan-Meier analysis with a BMI cut-off value of 24.25 was provided to designate survival curves in the whole cohort and a patient subgroup. To determine the independent predictors for mortality, a multivariate logistic regression model with the backward selection method was used. The variables with $p<0.1$ in Table 1 were entered the multivariate logistic regression and were reported in Table 2.

\section{Results}

The study included 78 patients: 11 men and 67 women. The mean age was $58.35 \pm 15.3$ years; the mean followup period was 33.7 months (maximum: 128 months). The patients were classified into two groups as the deceased (D) and the survived (S); 38 deaths (48.7\%) were noted during the follow-up. The comparison of the two groups regarding the demographic, clinical, echocardiographic, and hemodynamic characteristics at the baseline was presented in Table 1. The two groups were found to be similar in terms of gender, age, and the presence of AF. The median BNP level in group D was significantly higher than that in group $\mathrm{S}(\mathrm{p}<0.001)$. Baseline WHO FC III-IV was significantly more common in group D than that in group $\mathrm{S}(89.5 \%$ vs $57.5 \%, \mathrm{p}=0.003)$. Group D had significantly lower BMI and 6MWD compared to those

Table 1. Baseline clinical, echocardiographic and hemodynamic characteristics of the study population

\begin{tabular}{|c|c|c|c|}
\hline Characteristics & Survived $(n=40)$ & Deceased $(n=38)$ & $\mathbf{p}$ \\
\hline Age & $57.73 \pm 14.58$ & $59.03 \pm 16.21$ & 0.710 \\
\hline Gender (female) (\%) & $36(90 \%)$ & $31(81.6 \%)$ & 0.458 \\
\hline Atrial fibrillation (\%) & $10(25 \%)$ & $13(34.2 \%)$ & 0.520 \\
\hline WHO FC 3-4 (\%) & $23(57.5 \%)$ & $34(89.5 \%)$ & 0.003 \\
\hline Height (m) & $160.72 \pm 8.78$ & $160.10 \pm 8.16$ & 0.748 \\
\hline Weight(kg) & $78.55 \pm 16.07$ & $63.23 \pm 13.69$ & $<0.001$ \\
\hline BMI $\left(\mathrm{kg} / \mathrm{m}^{2}\right)$ & $30.46 \pm 6.20$ & $24.71 \pm 5.36$ & $<0.001$ \\
\hline 6MWD (m) & $330(300-390)$ & $270(140-320)$ & 0.017 \\
\hline \multicolumn{4}{|c|}{ Echocardiographic characteristics } \\
\hline TAPSE (mm) & $18(15-21)$ & $16(13-18)$ & 0.061 \\
\hline RVEDD (cm) & $3.61 \pm 0.95$ & $3.76 \pm 0.77$ & 0.519 \\
\hline Pericardial effusion (\%) & $10(25 \%)$ & $19(50 \%)$ & 0.040 \\
\hline \multicolumn{4}{|c|}{ Hemodynamic characteristics at heart catheterization } \\
\hline Systolic PAP (mmHg) & $72(54.5-84.75)$ & $70(62.5-82.75)$ & 0.673 \\
\hline Mean PAP (mmHg) & $44(31.25-52)$ & $42(38-54)$ & 0.539 \\
\hline $\mathrm{RAP}(\mathrm{mmHg})$ & $9(6-13)$ & $8(5-12.25)$ & 0.463 \\
\hline $\mathrm{CO}\left(\mathrm{L} / \mathrm{m}^{2}\right)$ & $4.89 \pm 1.60$ & $4.67 \pm 2.05$ & 0.607 \\
\hline $\mathrm{Cl}\left(\mathrm{L} / \mathrm{min} / \mathrm{m}^{2}\right)$ & $2.68 \pm 0.91$ & $2.68 \pm 1.11$ & 0.996 \\
\hline PVR (wood unit) & $7(4.03-9.55)$ & $8.72(5-13.1)$ & 0.076 \\
\hline BNP (pg/mL) & $207(100-433)$ & $614(281-1436)$ & $<0.001$ \\
\hline Hemogram (mg/dL) & $11.93 \pm 1.96$ & $11.98 \pm 2.32$ & 0.927 \\
\hline
\end{tabular}

WHO FC: World Health Organization Functional class, BMI: Body mass index, 6MWD: 6-minute walking distance, TAPSE: Tricuspid annular plane systolic excursion, RVEDD; Right ventricular end diastolic diameter; PAP: Pulmonary arterial pressure, RAP: Right atrial pressure, CO: Cardiac output, Cl: cardiac index, PVR: Pulmonary vascular resistance, BNP: Brain natriuretic peptide 
in group $\mathrm{S}(\mathrm{p}<0.001$ and $\mathrm{p}=0.017$, respectively). Of note, the rate of those with a BMI of $\geq 30$ was $21.1 \%$ in group $\mathrm{D}$ and $50 \%$ in group $\mathrm{S}(\mathrm{p}=0.002)$. The distribution of ACM during the follow-up period among different BMI categories was presented in Figure 1. (ACM rates were $100,59.3,40$ and $28.6 \%$ for BMI categories $\leq 20,20.01$ $24.99,25-29.99$, and $\geq 30$ respectively, $p=0.002$ ).

While the two groups had similar mean TAPSE, and RV end diastolic diameter, pericardial effusion was significantly more frequent in group D.

Multivariate logistic regression analysis showed that BMI [odds ratio $(\mathrm{OR})=0.632,95 \%$ confidence interval $(\mathrm{CI})=0.478-0.837, \mathrm{p}=0.001]$ and $6 \mathrm{MWD}(\mathrm{OR}=0.981,95 \%$ $\mathrm{CI}=0.970-0.993, \mathrm{p}=0.002)$ were independent predictors of mortality in this cohort (Table 2). The ROC curve analysis was performed to assess the utility of BMI as a predictor of mortality. The optimal BMI cut-off was $24.25 \mathrm{~kg} / \mathrm{m}^{2}$,

Table 2. Multivariate logistic regression analysis to predict mortality in patients with idiopathic pulmonary arterial hypertension

\begin{tabular}{|c|c|c|c|}
\hline & p & OR & CI 95\% \\
\hline 6MWD (m) & 0.002 & 0.981 & 0.970-0.993 \\
\hline BMI $\left(\mathbf{k g} / \mathbf{m}^{2}\right)$ & 0.001 & 0.632 & $0.478-0.837$ \\
\hline \multicolumn{4}{|c|}{$\begin{array}{l}\text { Variable(s) entered the model: Pericardial effusion, WHO FC3-4, 6MWD, } \\
\text { BNP, PVR, BMI, TAPSE } \\
\text { WHO FC: World Health Organization Functional class, 6MWD: 6-minute } \\
\text { walking distance, BNP: Brain natriuretic peptide, PVR: Pulmonary vascular } \\
\text { resistance, BMI: Body mass index, TAPSE: Tricuspid annular plane systolic } \\
\text { excursion, OR: Odds ratio, Cl: Confidence interval }\end{array}$} \\
\hline
\end{tabular}

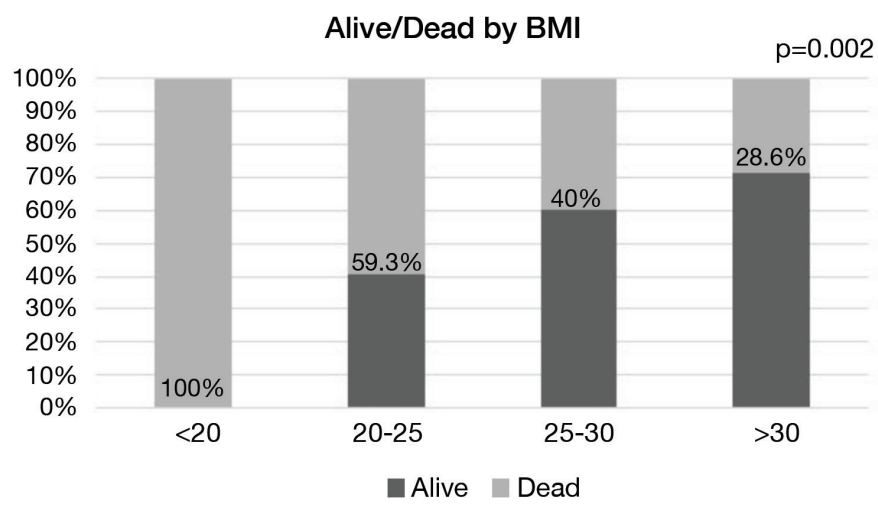

Figure 1. Distribution of ACM during follow-up among different BMI categories

ACM: All-cause mortality, BMI: Body mass index with $60.5 \%$ sensitivity and $82.5 \%$ specificity [area under the curve $(\mathrm{AUC})=0.759,95 \% \mathrm{CI}=0.654-0.864, \mathrm{p}<0.001]$ (Figure 2). As shown in Figure 3, the patients with a BMI of $\leq 24.25$ had worse prognosis based on the Kaplan Meier analysis survival curves (log-rank $\mathrm{p}<0.004)$.

\section{Discussion}

In this study, lower BMI was showed to be an independent predictor of death in patients with idiopathic PAH, which suggests an "obesity paradox" in these patients along with a different threshold. Specifically, a BMI of $\leq 24.25 \mathrm{~kg} / \mathrm{m}^{2}$ was the indicative of ACM although there was a linear decrease in ACM with increasing BMI categories.

Though increased BMI is a leading health problem, trials have shown favorable survival prognosis in obese patients in comparison with non-obese patients with various chronic disease such as hypertension, chronic obstructive lung disease, atherosclerotic cardiovascular disease and heart failure ${ }^{(8-13)}$.

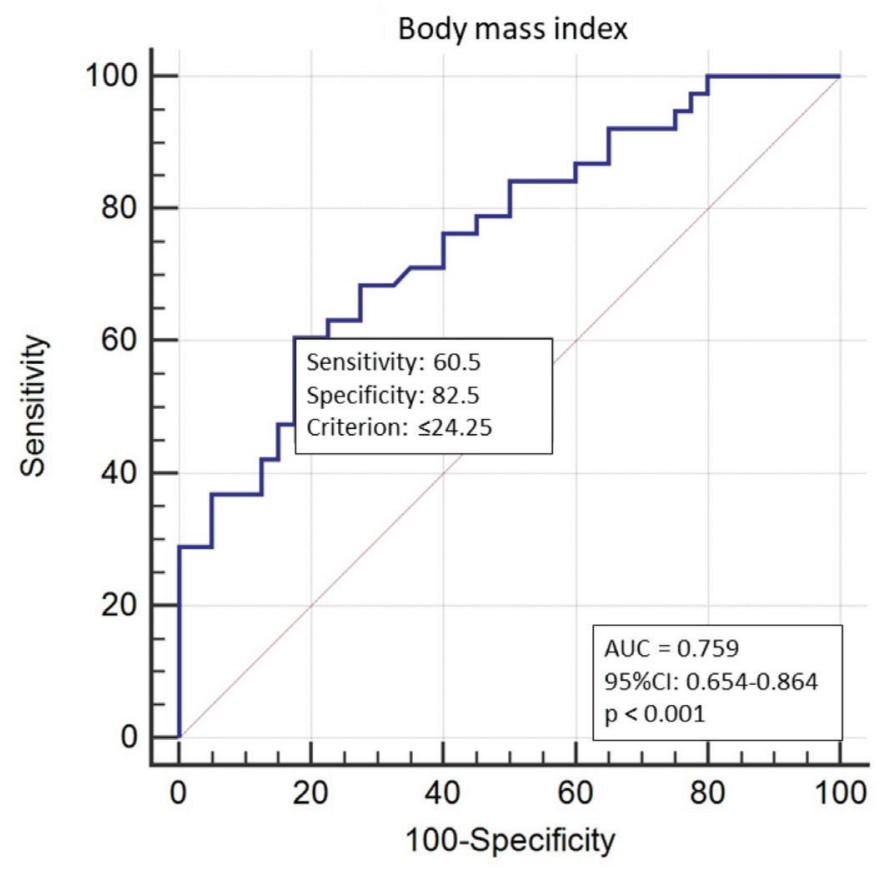

Figure 2. Receiver operating characteristic curves of BMI for predicting mortality

BMI: Body mass index, AUC: Area under the curve, Cl: Confidence interval 
The inverse relationship between obesity and ACM, which has been demonstrated in various cardiovascular conditions, challenged the simple clinical reasoning and created the term "obesity paradox"(14). This protective effect of obesity is particularly evident in heart failure patients with recent data supporting the concept of obesity paradox. This paradox is explained in part by the greater metabolic reserve of obese patients to cope with the increased oxidative stress, catabolic burden, and systemic inflammation associated with heart failure. The factors that were suggested to have a role in the relationship of low BMI with high mortality include abnormal secretion of cytokines and neurohormones, cardiac cachexia, and higher catabolic burden. Thus, the additional adipose tissue reserve might also provide a buffer for cytokines and improve the prognosis in patients with $\mathrm{PAH}^{(10,15-20)}$. Moreover, recent experimental studies have found that the upregulation of the renin-angiotensin system is strongly associated with the mortality in PAH.

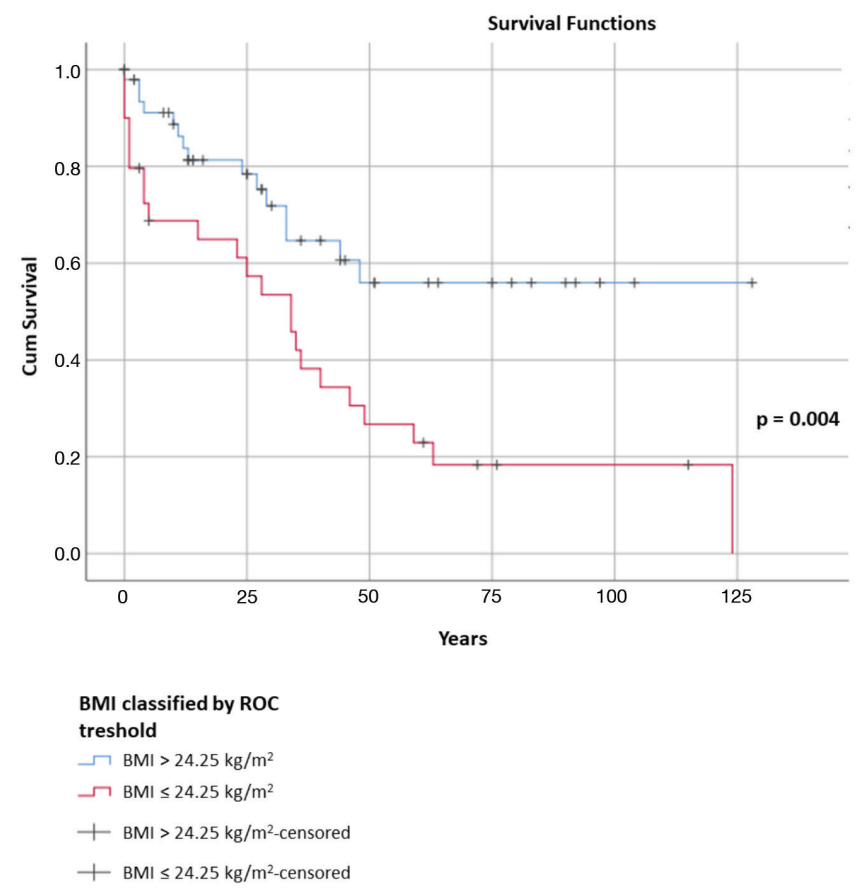

Figure 3. Kaplan-Meier survival estimates of mortality in patients with idiopathic pulmonary arterial hypertension by on admission $\mathrm{BMI}$ of $\leq 24.25$ vs $>24.25$

BMI: Body mass index, ROC: Receiver operating characteristic
Since obese patients have a weaker response to the reninangiotensin system, they might have an advantage in terms of mortality ${ }^{(20)}$.

It should be noted that there is no consensus regarding the paradox. Some studies reported similar findings and called it the "overweight paradox" rather than the "obesity paradox"(21). Others argue against it, reporting no survival advantage for obese patients ${ }^{(22)}$. On the contrary, the French network demonstrated a survival disadvantage for younger and morbidly obese patients ${ }^{(23)}$. Overall, these diverging opinions might be related to the cohort characteristics. Although we had a small number of patients with a BMI of $\geq 35$ ( $n=12)$ in our study, we did not observe any increase in the ACM but, rather, a continuing trend for decreasing ACM (16.7\%).

An important prognostic marker to assess the exercise capacity in patients with various pulmonary and cardiac diseases is $6 \mathrm{MWD}^{(24,25)}$. $6 \mathrm{MWD}$ was reported to be a predictor of mortality in $\mathrm{PAH}^{(26)}$. Similarly, we found that 6MWD was an independent predictor of ACM in this cohort of patients $(\mathrm{OR}=0.981,95 \% \mathrm{CI}=0.970-0.993$, $\mathrm{p}=0.002$ ).

\section{Study Limitations}

There are some limitations of the current analysis. First of all, the retrospective nature of the study is a limiting factor although the patients were closely monitored with regular follow-up visits at a specialized center in the region. Edema and diuretic treatment might have influenced the BMI, which was measured only at the time of diagnosis, and the patients' BMI might have changed over time. While BMI is the most commonly used measure of obesity, it does not report the distribution of adipose tissue throughout the body, and our study did not include data about the waist or hip circumference. Therefore, other measures of obesity, including waist-to-hip ratio or waist circumference, might be considered and compared to BMI in future studies to investigate the relationship between obesity and prognosis in PAH. 


\section{Conclusion}

BMI seems to be linearly but inversely related to allcause mortality among patients with idiopathic PAH.

\section{Ethics}

Ethics Committee Approval: The study was approved by Noninvasive Research Ethics Board of Dokuz Eylül University (desicion number: 2018/07-31).

Informed Consent: Because of the study's retrospective design, no patients' consents were added.

Peer-review: Internally and externally peer-reviewed.

\section{Authorship Contributions}

Concept: B.Ş., B.A., E.Ö., M.B.Y., B.Ö.K., D.S., K.C.T., C.S., Design: B.Ş., B.A., E.Ö., M.B.Y., B.Ö.K., D.S., K.C.T., C.S., Data Collection or Processing: B.Ş., B.A., E.Ö., M.B.Y., D.S., C.S., Analysis or Interpretation: B.Ş., B.A., M.B.Y., B.Ö.K., D.S., K.C.T., Literature Search: B.Ş., B.A., E.Ö., M.B.Y., D.S., Writing: B.Ş., B.A., M.B.Y., B.Ö.K., K.C.T., C.S.

Conflict of Interest: No conflict of interest was declared by the authors.

Financial Disclosure: The authors declared that this study received no financial support.

\section{References}

1. Tuder RM, Archer SL, Dorfmüller P, Erzurum SC, Guignabert C, Michelakis E, et al. Relevant issues in the pathology and pathobiology of pulmonary hypertension. J Am Coll Cardiol 2013;62:D4-12.

2. Afshin A, Forouzanfar MH, Reitsma MB, Sur P, Estep K, Lee A, et al. Health Effects of Overweight and Obesity in 195 Countries over 25 Years. N Engl J Med 2017;377:13-27.

3. Singh GM, Danaei G, Farzadfar F, Stevens GA, Woodward M, Wormser $\mathrm{D}$, et al. The age-specific quantitative effects of metabolic risk factors on cardiovascular diseases and diabetes: a pooled analysis. PLoS One 2013;8:e65174.

4. Dixon AE, Holguin F, Sood A, Salome CM, Pratley RE, Beuther David A, et al. An official American Thoracic Society Workshop report: obesity and asthma. Proc Am Thorac Soc 2010;7:325-35.

5. Young T, Skatrud J, Peppard PE. Risk factors for obstructive sleep apnea in adults. Jama 2004;291:2013-6.

6. Galiè N, Humbert M, Vachiery JL, Gibbs S, Lang I, Torbicki A, et al. 2015 ESC/ERS Guidelines for the diagnosis and treatment of pulmonary hypertension: The Joint Task Force for the Diagnosis and Treatment of
Pulmonary Hypertension of the European Society of Cardiology (ESC) and the European Respiratory Society (ERS): Endorsed by: Association for European Paediatric and Congenital Cardiology (AEPC), International Society for Heart and Lung Transplantation (ISHLT). Eur Heart J 2016;37:67-119.

7. Obesity and overweight. World Health Organization 2018. https://www. who.int/news-room/fact-sheets/detail/obesity-and-overweight (Last access: 22 May 2020)

8. Poirier P, Giles TD, Bray GA, Hong Y, Stern JS, Pi-Sunyer FX, et al Obesity and cardiovascular disease: pathophysiology, evaluation, and effect of weight loss. Arterioscler Thromb Vasc Biol 2006;26:968-76.

9. Lainscak M, von Haehling S, Doehner W, Sarc I, Jeric T, Ziherl K, et al. Body mass index and prognosis in patients hospitalized with acute exacerbation of chronic obstructive pulmonary disease. J Cachexia Sarcopenia Muscle 2011;2:81-86.

10. Fonarow GC, Srikanthan P, Costanzo MR, Cintron GB, Lopatin M, ADHERE Scientific Advisory Committee and Investigators. An obesity paradox in acute heart failure: analysis of body mass index and inhospital mortality for 108,927 patients in the Acute Decompensated Heart Failure National Registry. Am Heart J 2007;153:74-81.

11. Chittal P, Babu AS, Lavie CJ. Obesity paradox: does fat alter outcomes in chronic obstructive pulmonary disease? COPD 2015;12:14-8.

12. Lavie CJ, Sharma A, Alpert MA, De Schutter A, Lopez-Jimenez F, Milani RV, et al. Update on Obesity and Obesity Paradox in Heart Failure. Prog Cardiovasc Dis 2016;58:393-400.

13. Uretsky S, Messerli FH, Bangalore S, Cooper-DeHoff RM, Zhou Q, Pepine $\mathrm{CJ}$, et al. Obesity paradox in patients with hypertension and coronary artery disease. Am J Med 2007;120:863-70.

14. Gielen S, Sandri M. The obesity paradox — a scientific artifact? Int J Cardiol 2013;162:140-2

15. Horwich TB, Fonarow GC, Hamilton MA, MacLellan WR, Woo MA, Tillisch JH. The relationship between obesity and mortality in patients with heart failure. J Am Coll Cardiol 2001;38:789-95.

16. Curtis JP, Selter JG, Wang Y, Rathore SS, Jovin IS, Jadbabaie F, et al. The obesity paradox: body mass index and outcomes in patients with heart failure. Arch Intern Med 2005;165:55-61.

17. Casas-Vara A, Santolaria F, Fernandez-Bereciartua A, Gonzalez-Reimers E, Garcia-Ochoa A, Martinez-Riera A. The obesity paradox in elderly patients with heart failure: analysis of nutritional status. Nutrition 2012;28:616-22.

18. Oreopoulos A, Padwal R, Kalantar-Zadeh K, Fonarow GC, Norris CM, McAlister FA. Body mass index and mortality in heart failure: a metaanalysis. Am Heart J 2008;156:13-22.

19. Arena R, Lavie CJ. The obesity paradox and outcome in heart failure: is excess bodyweight truly protective? Future Cardiol 2010;6:1-6.

20. Lavie CJ, Alpert MA, Arena R, Mehra MR, Milani RV, Ventura HO. Impact of obesity and the obesity paradox on prevalence and prognosis in heart failure. JACC Heart Fail 2013;1:93-102.

21. Mazimba S, Holland E, Nagarajan V, Mihalek AD, Kennedy JLW, Bilchick $\mathrm{KC}$. Obesity paradox in group 1 pulmonary hypertension: analysis of the NIH-Pulmonary Hypertension registry. Int J Obes (Lond) 2017;41:11648. 
22. McLean LL, Pellino K, Brewis M, Peacock A, Johnson M, Church AC. The obesity paradox in pulmonary arterial hypertension: the Scottish perspective. ERJ Open Res 2019;5.

23. Weatherald J, Huertas A, Boucly A, Guignabert C, Taniguchi Y, Adir Y, et al. Association Between BMI and Obesity With Survival in Pulmonary Arterial Hypertension. Chest 2018;154:872-81.

24. Stahrenberg R, Duvinage A, Mende M, Gelbrich G, Auf Der Heide W, Düngen HD, et al. Determinants of submaximal exercise capacity in patients at risk for heart failure with preserved ejection fraction-results from the DIAST-CHF study. ESC Heart Fail 2015;2:76-84.
25. Deboeck G, Taboada D, Hagan G, Treacy C, Page K, Sheares K, et al. Maximal cardiac output determines 6 minutes walking distance in pulmonary hypertension. PLoS One 2014;9:e92324.

26. Miyamoto S, Nagaya N, Satoh T, Kyotani S, Sakamaki F, Fujita M, et al. Clinical correlates and prognostic significance of six-minute walk test in patients with primary pulmonary hypertension. Comparison with cardiopulmonary exercise testing. Am J Respir Crit Care Med 2000;161:487-92. 